\title{
Rir do outro: o fascismo das piadas racistas no cotidiano
}

\author{
Elise Helena de Morais Batista* \\ Maria Teresa de Arruda Campos**
}

\begin{abstract}
Resumo
Este trabalho pretende trazer para discussão as muitas provocações que as piadas carregam, formas divertidas de distração e de convívio entre amigos que ferem aqueles que são os motivos das piadas presentes nas salas de aula. Esse artigo visa analisar as piadas e apelidos presentes no cotidiano escolar em uma turma de $6^{\circ}$ ano de uma escola pública de Campinas/SP. O estudo ocorreu por meio de observações das aulas de Educação Física, registradas em um Diário de Campo, e de encontros entre pesquisadora e alunos em Grupo Focal. Como expressões do bullying, as piadas machucam uns e alegram outros, numa relação perversa de poder social. Por meio do estudo, foi possível constatar não apenas o cotidiano de piadas que desqualificam e fazem sofrem, mas também a necessidade de tempos e espaços de diálogo na escola, em que os alunos possam falar e ouvir sobre questões relacionadas ao meio sociocultural que vivem. As piadas racistas se presentificam como formas de racismo contra pessoas que, pelas suas diferenças e pela estranheza que provocam, são desqualificadas.

Palavras-chave: Microfascismo; Racismo; Humor; Bullying, Violência.
\end{abstract}

\section{Laughingof the other: fascism racist jokes in daily life}

\begin{abstract}
This paper aims to bring into discussion the provocations made by jokes, fun ways of distraction and conviviality among friends that hurt those who are the motives of these jokes in classrooms. This article aims to analyze the jokes and nicknames in school everyday life in a class of 6th grade of a public school in Campinas / SP. The study was conducted through observations of Physical Education classes, recorded in a field diary, and meetings between researcher and students in Focus Groups. As bullying expressions, jokes hurt some and rejoice others in a perverse relationship of social power. Through the study, it was possible to see not only the everyday jokes that disqualify and make sufferings, but also the need for time and space for dialogue at school, where students can speak and hear about issues related to socio-cultural environment in which they live. Racist jokes present themselves as forms of racism against persons who, through their differences and the strangeness that cause, are disqualified.
\end{abstract}

Keywords: Microfascism; Racism; Humor; Bullying; Violence.

\section{Introdução}

Não com a ira se mata, mas com o riso. (Nietzsche 1983, p.316)

Precisamos do riso. O riso faz a vida extravasar-se. Mas há que pensar em risos pela dimensão do sentido que cada riso carrega? A questão aqui levantada aponta para um certo tipo de riso que denuncia o que nos motiva a rir, especialmente o que produz o rir de alguém e o que produz em outro alguém que ri. Não pensamos quando rimos o que é rir de um outro que nos provoca, pela diferença que produz eco em nós, que reflete uma certa diferença que pode incomodar, algum desconforto. Esse riso seria um disfarce? Um medo? Revelaria o que é para ficar escondido?

Escrever sobre o riso é tarefa difícil, trata-se de escrita que produz efeitos de verdade. Faz rever a vida, o que toca, o que significa. Assim, a escrita como exercício pessoal feito por si e para si é uma arte da verdade díspar; ou, mais precisamente, uma maneira racional de combinar a autoridade tradicional da coisa já dita com a singularidade da verdade que nela se afirma $e$ a particularidade das circunstâncias que determinam seu uso (FOUCAULT, 2004a, p.151).

Não há palavra livre de sentido, são significados múltiplos que nos penetram, que criam realidades, que têm força, que dirigem nossos pensamentos, os modos de vida, as relações com as pessoas, com o mundo que vivemos e conosco, como afirma Larrosa (2002, p. 20):

[...] O homem é um vivente com palavra. E isto não significa que o homem tenha a palavra ou a linguagem como uma coisa,

*Coordenadora Pedagógica da Prefeitura Municipal de Campinas. Endereço eletrônico: elisehelena2000@ yahoo.com.br

${ }^{* *}$ Superintendente do Arquivo Público e Histórico de Rio Claro. Endereço eletrônico: teresa.arruda2010@gmail.com 
ou uma faculdade, ou uma ferramenta, mas que o homem é palavra, que o homem é enquanto palavra, que todo humano tem a ver com a palavra, se dá em palavra, está tecido de palavras, que o modo de viver próprio desse vivente, que é o homem, se dá na palavra e como palavra. Por isso, atividades como considerar as palavras, criticar as palavras, eleger as palavras, cuidar das palavras, inventar palavras, jogar com as palavras, impor palavras, proibir palavras, transformar palavras etc. não são atividades ocas ou vazias, não são mero palavrório. Quando fazemos coisas com as palavras, do que se trata é de como damos sentido ao que somos e ao que nos acontece, de como correlacionamos as palavras e as coisas, de como nomeamos o que vemos ou o que sentimos e de como vemos ou sentimos o que nomeamos.

$\mathrm{O}$ riso que vem de uma piada contada dramaticamente pode ser uma descoberta de um outro saber fora de si, de alguns personagens de corpo e alma que são nomeados pelo seu lado de fora, que nos conclama a pensar que "é preciso compreendê-la menos como um deciframento de si por si, do que como uma abertura que se dá ao outro sobre si mesmo" (FOUCAULT, 2004a, p.157).

Esse artigo, fruto da relação entre duas pesquisas realizadas no grupo VIOLAR, expõe essa forma de fazer rir pela piada, denunciando os preconceitos velados de um grupo que se nomeia não racista, mas que faz rir dos negros, desqualificando pessoas pela sua pele. A escola, espaço de relações onde se aprende a conviver, a olhar para quase todas as diferenças presentes na sociedade, apresenta manifestações de agressividade pelos apelidos, pelas piadas e pelas discriminações estigmatizadas, quase sempre silenciando e pouco fazendo para que sejam refletidas.

Para Larrosa (1994, p.81):

[...] a própria experiência de si não é senão $o$ resultado de um complexo processo histórico de fabricação no qual se entrecruzam os discursos que definem a verdade do sujeito, as práticas que regulam seu comportamento $e$ as formas de subjetividade nas quais se constitui sua própria interioridade.

As piadas racistas produzem efeitos de verdade e a possibilidade de subjetivar-se a partir da fala de si e dos efeitos do outro sobre si numa relação ética para dentro e para fora. Foucault, com o pseudônimo Maurice Florence ${ }^{1}$, apresenta em 1984, no verbete intitulado "Foucault", a subjetividade como "[...] a maneira pela qual o sujeito faz a experiência de si mesmo num jogo de verdade, no qual ele se relaciona consigo mesmo" (FOUCAULT, 2004b, p. 236).

Gallo (2009), no artigo "Entre Édipos e O Anti-Édipo", trabalha com o riso contra o fascismo e inicia com uma citação de Oswald de Andrade, de 1928, que diz "A alegria é a prova dos nove. Só a antropofagia nos une". Essa possibilidade do riso alegre, que libera e potencializa, que alegra e mobiliza, que nos engole e somos engolidos, foi um dos marcos que aparecem quando se abordam as piadas. Nas artes do corpo como o clown, onde eles riem de si, mostrando-se abobalhados diante de situações embaraçosas, ou nas comédias de costumes de Moliére, o riso assume seu lado alegre. Questiona sem machucar, faz rir sem desqualificar.

As sociedades também elaboram seus motivos para rir a partir da concepção construída pela cultura dominante, e que aparecem nos sinais de racismo naturalizados pelas piadas e apelidos. Episódios como a tragédia envolvendo grupos radicais religiosos e o jornal semanal francês "Charlie Hebdo" denunciaram recentemente o quanto não há neutralidade nas provocações que o riso carrega, os sentidos que trazem em suas manifestações, as dores e o ódio que podem desencadear.

Quais seriam os risos no cotidiano das escolas, nas relações entre os alunos, entre alunos e professores? Risos estes que não se distanciam daqueles que ecoam fora dos muros da escola, nas ruas, nas casas, nas TVs e programas de rádio. $\mathrm{O}$ que nos dizem esses risos provocados por piadas inventadas, apelidos criados? Com o objetivo de conhecer melhor as relações entre os alunos por meio das piadas que fazem rir e fazem chorar, esse trabalho observou e ouviu jovens alunos de $6^{\circ}$ ano em uma escola estadual da cidade de Campinas/SP.

\section{Piadas que fazem rir... piadas que fazem chorar...}

Rir é muito bom, mas não pode ser naturalizado sempre como potência, algo bom e positivo. Os risos socialmente construídos e as diferentes formas que vão sendo instauradas, na contemporaneidade, têm trazido uma falta de 
sensatez provocada pela desqualificação, liberando tristeza, ressentimentos, lágrimas e até prazeres. São tantos os risos. Elencamos ainda o riso, parente da arte posta no circo, no teatro, na televisão, do riso das brincadeiras entre crianças e jovens, que se apelidam em suas características singulares, do riso irônico, nascido do desprezo quando se perde uma disputa... São tantos risos possíveis!

As piadas, muitas delas, provocam o riso ao apontarem para alguma diferença que sobressai. Traços singulares, que provocam alguma reação, seja pelo viés da sexualidade, pelo gênero, pela etnia, pela idade, pela nacionalidade, pela deficiência física, estão entre alguns dos focos das piadas contadas nas reuniões entre amigos ou nas mesas descontraídas dos bares.

A Modernidade inventou e se serviu de uma lógica binária, a partir da qual denominou de diferentes modos o componente negativo da relação cultural: marginal, indigente, louco, deficiente, drogadito, homossexual, estrangeiro etc. Essas oposições binárias sugerem sempre o privilégio do primeiro termo e o outro, secundário nessa dependência hierárquica, não existe fora do primeiro, mas dentro dele, como imagem velada, como sua inversão negativa (DUSCHATZKY; SKLIAR, 2001, p.123).

Assim, criam-se definições sobre pessoas e suas características que as classificam e enquadram em rótulos que por si qualificam: "Dessa forma, o estereótipo, que é uma de suas principais estratégias discursivas, acaba sendo uma modalidade de conhecimento e identificação que vacila entre aquilo que está sempre em um lugar já conhecido, ou melhor, esperado, e algo que deve ser ansiosamente repetido." (ibidem, p.123).

Andrade (2007, p. 98) explica que "aquilo que é produzido histórica e culturalmente não reflete apenas como nós nos vemos e aos outros, mas de que modo nos comportamos cotidianamente com relação a nós mesmos e aos outros".

Não há cultura sem troca, há dinamismo na cultura, movimento que produz esse outro olhar para o mundo e para as relações sociais passíveis de mudanças. Pela cultura nos olhamos, criamos um certo modo de pensar sobre nós mesmos e sobre os outros. O riso e o risível, nesse sentido, o que faz alegrar a vida e o que faz sofrer, são possibilidades humanas construídas socialmente de formas diferentes, determinadas pelas produções culturais de dado momento histórico. Não há como não olhar para o riso sádico, presente nos programas humorísticos, nas "pegadinhas" dos programas de auditório aos domingos, nos espetáculos teatrais, nas músicas, para dar alguns exemplos.

Essa prática antiga de ridicularizar publicamente alguém pelos seus traços de diferença tem sido nomeada de bullying que, segundo Oliveira e Votre (2006), é a forma mais primária de violência, manifestada por gestos, palavras e ações, tendo na linguagem gestual e verbal sua concretização mais comum. Essa éuma prática antiga, entretanto, nos últimos anos mobilizou a criação e implantação de legislação específica e de manuais didáticos que ensinam, no papel, como os "envolvidos" devem se comportar frente às manifestações de bullying além de classificar, grande parte dessas abordagens, os alunos como agressores, vítimas ou testemunhas ${ }^{2}$.

Entretanto, em uma análise crítica do conceito, é possível observar que muitas abordagens atuais sobre o bullying afirmam e reafirmam classificações e verdades estabelecidas e discursadas sobre o fenômeno, esquivando-se de problematizá-lo. Ao ser intensivamente citado nos meios midiáticos e na criação de leis e programas de combate ao bullying nas escolas, mais o conceito aproxima-se de visões baseadas no senso-comum, presente na conversa de alunos, educadores, famílias, da sociedade em geral, conotando a este um tom até mesmo cômico. Para ilustrar, é comum ouvir conversas em que uma simples brincadeira (e, nesse caso, brincadeira mesmo) é imediatamente relacionada ao termo bullying, seguindo-se risos, evidenciando que o termo não traz a seriedade com que deveria ser tratado.

Para Antunes e Zuin (2008), ao classificarem os "tipos" de violência, os homens têm a ilusão de conseguirem controlá-la. Porém, ao serem classificados, os fenômenos tornam-se naturais e as raízes de sua existência são deixadas de lado, convertendo-se em meros números e dados estatísticos. A contradição reside no fato de que, ao serem tratados como naturais, passam a exercer poder sobre o homem e tornam-se mais incontroláveis, mascarados pelo rótulo da ciência:

Observa-se que os pesquisadores, de forma geral, ao dissertarem sobre as supostas "causas" do que chamam bullying, dentre as quais se destacam os fatores econômicos, sociais, culturais e particulares, não as problematizam (...) Desta forma, as 
influências familiares, de colegas, da escola $e$ da comunidade, as relações de desigualdade e de poder, a relação negativa com os pais e o clima emocional frio em casa parecem considerados naturais $e$ apartados das contradições sociais que os produziram (ANTUNES; ZUIN, 2008, p. 36).

De acordo com os autores, para que atitudes simplistas não sejam encaradas como a solução definitiva para os problemas, é necessário que as definições dos conceitos sejam estudadas à luz das mediações sociais que as determinam, ou seja, não se deve ignorar as razões sociais mais amplas que geram a violência, pois são essas que devem ser modificadas: as raízes de sua existência.

Simples é pensar em cenas de nossas vidas onde vimos, ouvimos ou fizemos coisas como apelidar, intimidar, perseguir, empurrar, ridicularizar, inibir, humilhar, discriminar, assediar, roubar, constranger, achincalhar, ignorar, agredir, aterrorizar, tiranizar, coagir, caçoar, ofender, ferir, ameaçar, dominar, forçar, bulir, sem que nos déssemos conta do que cada uma delas poderia tatuar algum tipo de dor em alguém.

Essa maneira sutil e velada de viver o preconceito fortalece o padrão de negação de uma sociedade que encara o outro como seu igual e se incomoda com isso precisando negá-lo, eliminá-lo. É surpreendente tanta gente conhecer alguém preconceituoso, afirmar que o preconceito existe e ao mesmo tempo termos um índice muito menor de admissão pessoal do preconceito (CAMPOS, 2013, p. 23).

Para Abramovay (2006), bullying é um nome novo para uma das diversas violências que existem há muito tempo nas escolas, referente à intimidação do outro e à sua ridicularização, por meio do constrangimento e coação. A autora pontua que nosso país possui um contexto diferente do norueguês no qual o termo se originou e, por esse motivo, prefere não utilizar a palavra. Abramovay (2006, p. 16) acredita que, no Brasil, há outros fatores sobre a violência que não se resumem ao "gordinho" ou à "menina sardenta de óculos", pois em nosso país há manifestações de racismo próprios da localidade: "Naquele país - Noruega -, os alunos não ameaçam de morte os professores, nem os professores retrucam xingando os alunos de "picolé de breu", "picolé de asfalto" ou "toalha de mecânico" etc., todas manifestações do imenso racismo que existe no Brasil".

De fato, ao importar um conceito, é necessário repensá-lo e contextualizá-lo. Na verdade, o ponto essencial é justamente problematizar os significados do conceito a partir do contexto em que é vivenciado. Se no Brasil há uma configuração própria que se refere ao racismo, é necessário pensar no bullying nesse sentido.

Até que ponto os atuais programas, projetos e leis de combate ao bullying têm refletido sobre as verdadeiras causas de sua ocorrência? ${ }^{3}$ Será que estes têm levado os alunos a refletirem sobre os próprios preconceitos? Nas pautas de tais programas constam os objetivos de respeito e tolerância ao outro, mas quem é este outro a quem devemos aprender a tolerar e respeitar? Ora, se não houvesse os preconceitos que estão ainda vívidos nas relações cotidianas, haveria bullying? Se não houvesse os estereótipos de beleza, propagados inclusive pela mídia que é a primeira a trazer um discurso moral sobre o bullying, será que alguns seriam menosprezados em detrimento de características sociais e culturalmente valorizadas? Afinal, o bullying é originado pelos chamados "agressores" ou faz parte de todo um sistema que aplaude piadas infames nos programas televisivos e em comentários sarcásticos feitos pelos próprios professores ${ }^{4}$ contra seus alunos?

Assim, é necessário analisar o bullying por meio de um olhar ampliado, considerando os aspectos socioculturais, pois o fenômeno é uma expressão de como as relações cotidianas são vivenciadas, vinculadas às mensagens repetidamente transmitidas pela mídia, instituições sociais, entre outros.

O Brasil não é um país livre de preconceitos, em especial, àqueles referentes a questões étnico-raciais, religiosas ou geracionais. Segundo Gonçalvez e Silva (2002), o mito da democracia racial foi um dos maiores mecanismos de dominação ideológica produzido no mundo, ainda atual. A discriminação contra vários grupos permaneceu viva e real, em um jogo no qual os diferentes são ao mesmo tempo exaltados e excluídos. Como afirma Pierucci (1990), o racismo surge não da negação da diferença, mas sim de sua exaltação, pois a rejeição das diferenças ocorre após a afirmação das mesmas.

Nosso país possui um alto índice de preconceito racial, facilmente identificado quando analisamos o "Mapa da Violência: A cor dos 
homicídios no Brasil", o qual revela, em suas considerações finais, um diagnóstico da realidade dos homicídios de negros e, sobretudo, de jovens negros:

Entre 2002 e 2010, segundo os registros do Sistema de Informações de Mortalidade, morreram assassinados no país 272.422 cidadãos negros, com uma média de 30.269 assassinatos ao ano. Só em 2010 foram 34.983 (...).

- Considerando o conjunto da população, entre 2002 e 2010 as taxas de homicídios brancos caíram de 20,6 para 15,5 homicídios - queda de 24,8\% - enquanto a de negros cresceu de 34,1 para 36,0 aumento de 5,6\%.

- Com isso a vitimização negra na população total, que em 2002 era 65,4 morriam assassinados, proporcionalmente, 65,4\% mais negros que brancos, no ano de 2010 pulou para 132,3\% proporcionalmente, morrem vitimas de homicídio $132,3 \%$ mais negros que brancos.

- As taxas juvenis duplicam, ou mais, às da população total. Assim, em 2010, se a taxas de homicídio da população negra total foi de 36,0 a dos jovens negros foi de 72,0 (WAISELFISZ, 2012, p. 38).

Precisamos pensar em todas as ações que acabam provocando esses altos índices de incidência da questão racial na violência letal do Brasil. Os números apresentam proximidade às regiões do mundo que atravessaram conflitos armados internos ou externos. Difícil é a constatação de que a mortandade no país cresce na sua juventude e que o foco principal está na sua pele.

Essa reflexão sobre o que estamos fazendo de nossas vidas, o que estamos deixando que façam conosco, nossas omissões com a vida coletiva, nos prendem em armadilhas onde vamos criando (im)possibilidades de viver alegremente, presos a desejos outros criados pela mídia, que pauta formas outras de relacionamentos a partir de padrões racistas e excludentes. Entregamo-nos aos programas de televisão que incentivam a competição custe o que custar, pagamos altos preços por ingressos de espetáculos stand up, que apontam para essa forma de olhar o outro e qualificá-lo como inferior a nós, como também os apelidos que se explicam ingenuamente com a frase "era só uma brincadeira".

Conforme Campos (2013, p. 29)

Dá-me um aperto na garganta pensar em quantas crianças crescem ouvindo esse modo de falar sobre elas na sala de suas casas, penso no preço que se paga para assistir a esse tipo de espetáculo, o quanto as crianças negras, e aquelas que já se descobrem diferentes por não se reconhecerem no corpo que têm sofrem ao ouvir falar sobre si do jeito que se fala. Sentir-se menos, inferior, olhar no espelho e se achar feia, ser dona de "cabelo ruim", não ter coragem de se expor em seus sentimentos, porque tudo que ouviu foram desafetos, são questões que tomam conta de mim e fazem desse trabalho, além de um trabalho da academia, um pedido de socorro: temos que fazer algo ${ }^{5}$.

Mas pensar no binômio tolerância/intolerância com o apelo social que as múltiplas práticas reivindicam nos leva a Duschatzky e Skliar (2001, p.153): "Por um lado, a tolerância convida a admitir a existência de diferenças; no entanto, nesse mesmo convite reside o paradoxo, já que se trata de aceitar o diferente como princípio, também se tem de aceitar os grupos cujas marcas são os comportamentos antissociais ou opressivos".

\section{Os racismos que fazem rir}

Com o objetivo de compreender como as interações entre os alunos ocorriam no cotidiano escolar, foi realizado um estudo em uma escola estadual da cidade de Campinas, interior de São Paulo, entre os anos de 2009 e 2011 (BATISTA, 2011). A professora-pesquisadora acompanhou os alunos de oito turmas de $6^{\circ} \mathrm{s}$ anos e registrou as observações das aulas de Educação Física e demais momentos escolares em um Diário de Campo, com o objetivo de registrar, narrar e situar os acontecimentos do cotidiano (TURA, 2003).

No ano de 2010, a partir dos registros do Diário de Campo, quinze alunos foram convidados para compor um Grupo Focal, uma técnica de pesquisa que tem como objetivo principal conhecer o modo de ser e pensar dos participantes (GATTI, 2005), intencionando compreender como os alunos vivenciam as diferenças na escola e conhecer quais 
as concepções e opiniões que eles apresentam.

A partir de observações realizadas no Diário de Campo e nos debates do Grupo Focal (GATTI, 2005), foi possível observar como o contexto de xingamentos e brincadeiras que ofendem estavam presentes no cotidiano e na dinâmica de interação entre esses alunos de 11 e 14 anos. No encontro do Grupo Focal, os estudantes relataram alguns dos apelidos e xingamentos que ouviam ou proferiam cotidianamente: "lontra"; "caminho de rato", "pica-pau", "tucano" (em referência ao cabelo de um colega); "a chuva enferrujou", "o pai teve vontade de chupar prego enferrujado" (em referência ao colega ruivo); "minhoca de água doce".

Segundo Oliveira e Votre (2006, p. 175), "Os rótulos discriminadores, de base metafórica, são criativos, provocam o riso e a diversão dos circunstantes e, se não fossem trágicos, poderiam ser considerados manifestações da arte da linguagem na interação cotidiana". Ao observar os apelidos listados pelos alunos, é perceptível o que os autores pontuam, pois são deveras muito criativos, porém trágicos. Tão criativos são esses apelidos que até mesmo nos congressos científicos em que a professora-pesquisadora participou, ao apresentar este e outros dados da pesquisa empírica em relação às agressões verbais, presenciou risos daqueles que assistiam à exposição do estudo. Afinal, porque é tão engraçado o agredir o outro, o humilhá-lo a partir de alguma característica que o diferencia? E constatar... isso não está presente apenas na escola!

As diferenças socialmente desvalorizadas, ao surgirem como juízos de valor e estereótipos que inferiorizam uns em detrimento de outros, provocam dor, tristeza e exclusão. Dentre as diferenças, a questão da raça, etniae cor da pele, em parte problematizadas nos dados do Mapa da Violência (WAISELFISZ, 2012), apareciam como uma das características mais impulsionadoras dos termos "criativos", utilizados para xingamentos. Como afirmou Murilo, um dos alunos participantes do Grupo Focal:

Macaco é o que eu mais xinguei já na minha vida (...). Eu já xinguei os outros de preto, já xinguei os outros de carvão... macaco, chimpanzé, por causa que era preto, eu xinguei isso, mas agora eu não xingo mais... (GRUPO FOCAL, 2010).

Oliveira (2003, p. 3) afirma que:
... a partir do momento em que na interação social as diferenças passam a ser objeto de atribuição de significados, hierarquizando a espécie humana, surge a discriminação que, dando origem à desigualdade, torna-se impedimento para que a justiça social se estabeleça, e consequentemente é negado aos discriminados o direito à cidadania.

No contexto da pesquisa, evidenciou-se a história de Márcia ${ }^{6}$, que ilustra de forma significativa a violência sofrida não apenas pelo fato de ser uma garota obesa mas, sobretudo, por ser negra. Alvo de humilhações e risadas de seus colegas, era chamada de "cotonete de elefante" em referência aos seus cabelos, dentre outras expressões que a associavam à sujeira e à feiura. Por meio dos registros do Diário de Campo, evidenciou-se que os ocorridos com a aluna poderiam se enquadrar nas especificidades do que se denomina bullying, por ser alvo constante das piadas de seus colegas e, sobretudo, exemplo do racismo presente nas relações entre os alunos.

A exclusão sofrida por Márcia era conhecida por muitos alunos, como expressa uma redação realizada por uma colega de turma: "na minha sala tem uma amiga chamada Márcia, só porque ela é meio fofa todos na sala de aula ficam xingando ela, a maltratando, falando piadinhas contra ela, até eu já soltei umas piadinhas" (Redação $6^{\circ}$ ano I, nov. 2009).

Em outras turmas, sua história também era conhecida, explicitando como as agressões se estendiam aos demais espaços escolares: "Márcia é uma menina que estuda no $6^{\circ}$ ano. Ela é uma menina gorda, feia, cabelo de burro, isso é o que eu escuto dentro da sala, no pátio e até fora da escola" (Redação $6^{\circ}$ ano F, nov. 2009).

Em um dos registros do Diário de Campo (2009), na observação de uma aula de Educação Física em que Márcia foi ofendida em relação à sua obesidade, alguns alunos chegaram-se à professorapesquisadora e fizeram outras revelações. Relataram que Márcia, por diversas vezes, sofria xingamentos de outros alunos, com as seguintes referências: "Márcia é suja e encardida"; "Seu cabelo é "bombril' e sua mãe utiliza-o para lavar louça"; "Márcia deveria passar álcool em gel no cabelo e para limpar-se" (DIÁRIO DE CAMPO, agos., 2009).

E o porquê esse rir do outro se faz presente com tanta intensidade? Rir a partir de criativas e cruéis piadas, que expressam os preconceitos, que 
calam, intimidam e/ou revoltam aqueles que recebem as ofensas? Aos serem questionados no Grupo Focal sobre as razões que atribuíam à existência da violência, os alunos presentes relataram que aqueles que xingam e humilham seus colegas o fazem para sentirem-se superiores e melhores que os outros e para fazerem sucesso entre o grupo.

No Encontro 1 do Grupo Focal, ao serem questionados sobre as razões do "agredir o outro", as palavras e expressões ouvidas foram: "raiva", "o outro te xinga e você não aguenta", "se achar o tal", "humilhar o outro e assim se sentir melhor". Além disso, os alunos também disseram que as agressões verbais ocorrem para os colegas darem risada e "zuarem juntos". Segundo o grupo, aqueles que humilham não ligam para os sentimentos da pessoa ofendida e, os "mais fracos", que não conseguem se defender, acabam sendo os mais agredidos pela turma.

Outra hipótese formulada pelas garotas presentes no Grupo Focal sobre as possíveis razões da violência no ambiente escolar foi o "revidar com agressãoa violência sofrida anteriormente”. Essa parece ser a estratégia para viver no atual sistema, o capitalismo, em que a competição é exacerbada no conhecido "cada um por si", onde cada um busca, individualmente, ser o vitorioso nesse "jogo" em que uns ganham e outros perdem.

Como relata Türcke (2010, p. 20), “a pressão concorrencial pertence ao capitalismo assim como a pressão sanguínea, ao corpo". Essa concorrência está presente em várias instâncias da sociedade, desde grandes empresas e produtos como nas relações cotidianas. Em todas elas, a busca é por ser percebido, pois só existe aquilo que aparece, que está "aí" (TÜRCKE, 2010). Não seria a violência uma forma de estar "aí", de se fazer percebido?

Em nossa sociedade, parece ter se naturalizado o agredir como forma de vivenciar as relações sociais e, com isso, não são experimentadas outras maneiras de agir frente às agressões, sendo a única estratégia a própria agressão. Colombier (1989, p. 51), ao estudar a violência escolar, relata que a mesma "nasce da palavra emparedada", pois, segundo a fala de um aluno "Porque não podemos nos vingar de outra maneira".

Segundo a autora:

Palavra emparedada. Quais são as classes, as horas de curso, onde os alunos têm a possibilidade de analisar o que lhes acontece e de falar sobre isso? (...) A violência é um discurso da recusa. Frente a esta situação, parece urgente criar lugares $e$ tempo para a palavra. Inventar estratagemas para que seja dito, ou às vezes escrito, o que não vai bem. Mas sem ingenuidade, não se trata de cair numa ideologia de consenso, acreditar que falando todo mundo vai ficar de acordo. Mas, ao contrário, é preciso levar em conta os conflitos e organizar os meios para sua resolução (COLOMBIER, 1989, p. 82).

Esse riso sádico, que machuca, expressa os racismos, preconceitos e estereótipos pulsantes no meio sociocultural dos alunos. Como uma "herança" que se perpetua dos mais velhos para os mais jovens, concebe-se normal o rir de alguém, sem considerar ou imaginar os sentimentos provocados. Uma forma de violência que deve ser problematizada por meio do diálogo com as crianças, adolescentes e jovens. Que as "palavras emparedadas" tornem-se livres para irem ao encontro daqueles que em alguns momentos são oprimidos, em outros momentos oprimem, em um círculo vicioso que tende a continuar seu movimento enquanto as "paredes" mantiveram-se rígidas nos espaços sociais que podem problematizá-la, sobretudo a escola.

\section{Considerações finais}

O tema aqui tratado não merece conclusão. Não merece conclusão porque não é possível que fechemos em algum conceito aquilo que adoece quem pratica e quem é vítima. Não merece conclusão porque faz mal ao processo civilizatório desse momento histórico que se conclua que grande parte das piadas, quase a totalidade dos apelidos ainda servem para estabelecer relações de poder, relações discriminatórias e consequente tentativa de exclusão de um grupo sobre outros. Uma sociedade adoecida como a nossa quase não encontra motivos para rir que não seja esse riso sádico que desde os bancos escolares aparece com frequência naturalizado como "zoar", "brincadeira", dando sucesso e fama àqueles que melhor desempenham essa função.

Dar nome às coisas e a estas coisas aqui tratadas nos remete àquela Alice dos contos de fada que, em sua simplicidade, questiona a necessidade que temos, em lugar de viver dignamente, rotular, colocando em uma etiqueta aquilo que queremos dizer sobre alguém. 
Discutindo os nomes dados, temos Campos (2008, p. 56):

A verdade tatua sem pedir licença, marcando um jeito de viver e de conviver que 'dita' formas de relacionamento, cria desejos, formula teses, cristaliza sentimentos. A verdade parte do princípio de que é preciso que haja uma explicação, que para 'aquilo' se tenha definido cada questão, cada passo, cada cor, cada cheiro, cada vida. Cerca-se cada sujeito de padrões e se constrói um modelo onde ser assim é definido de tal e tal maneira.

A literatura infantil, muitas vezes dirigida aos 'adultos', como exposto nesse trecho clássico pode apresentar questões que extrapolam o que as crianças podem captar, mas que trazem sua mensagem para os leitores, aqueles que na calada da noite, sentam na cama da criança e leem para ela:

Os insetos lá não me dão prazer, na verdade - explicou Alice - porque tenho medo deles, pelo menos dos maiores. Mas posso lhe dar o nome de alguns.

- Naturalmente eles atendem pelo nome observou distraidamente o Mosquito.

- Nunca ouvi dizer que fizessem isso.

- E de que serve então, eles terem nomes, se não atendem por esses nomes?

Estranhou o Mosquito.

- Para eles, não serve de nada - Alice explicou. - Mas é útil para as pessoas que dão os nomes, eu acho. Se não, porque dar nomes às coisas? (CARROL, 1980, apud Campos, 2008, p.56).

\section{Notas}

1 Maurice Florence, M. F., abreviatura de Michel Foucault. Este verbete aqui citado em parte foi originalmente publicado no 'Dictionnaire des philosophes', Paris, PUF, 1984, sob a direção de Denis Huisman.

2 Há diferentes formas de nomear os envolvidos em bullying. Alguns estudos, como Lopes Neto (2005), adotam os termos "autor de bullying" (agressor), "alvo de bullying" (vítima), "alvo/autor de bullying" (agressor/ vítima) e "testemunha de bullying". Em Fante (2005) encontramos os termos "vítima típica", "vítima provocadora", "vítima agressora", "agressor" e "espectador".

3 Tais programas não serão analisados neste artigo, entretanto esta reflexão se faz necessária.

4 Sobre essa discussão recomendamos Zuin (2008).

5 A pesquisa relatada no vídeo disponível em $<$ http://www.youtube.com/watch?v=L5Qn3OJk_ Z4>, dia 08 de agosto de 2012, 10h04, ajuda a compreender o conceito que as crianças negras podem formar de si mesmas devido aos estereótipos atribuídos aos negros.

6 O nome é fictício, com o objetivo de preservar a identidade da estudante.

\section{Referências}

ABRAMOVAY, Miriam. Entrevista. Dialogia. São Paulo, v. 5, p. 15-22, 2006.

ANDRADE, Maria Celeste de Moura. O Cotidiano Escolar como Espaço de Produção de Sujeitos Cidadãos. In: Camargo, Ana Maria e Mariguela, Marcio (orgs). Cotidiano Escolar: Emergência e Invenção. Piracicaba: Jacintha Editores, 2007.

ANTUNES, Deborah Christina; ZUIN, Antônio Álvaro Soares. Do bullying ao preconceito: os desafios da barbárie à educação. Revista Psicologia \& Sociedade. v. 20, n. 1. Porto Alegre, Jan./ Apr. 2008. Disponível em: <http://www.scielo.b r/scielo.php?script=sci_arttext\&pid=S01021822008 000100004>. Acesso em: 01 de ago. de 2008.

BATISTA, Elise Helena de Morais. Bullying $e$ diferenças: a busca por um olhar ampliado. Dissertação de Mestrado. Universidade Estadual de Campinas, Faculdade de Educação, 2011. Disponível em http://www.bibliotecadigital.uni camp.br/document/?code $=000843831$.

CAMPOS, Maria Teresa de Arruda. Tá Rindo de Quem? O negro e o gay como motivo de piadas. Tese de doutorado. Universidade Estadual de Campinas, Campinas, SP, 2013.

CAMPOS, Maria Teresa de Arruda. A Adolescência Inventada e os Sujeitos que se Inventam na Participação Social: capturas e rupturas. Dissertação de Mestrado. Universidade Estadual de Campinas, Campinas, SP, 2008. 
COLOMBIER, Claire. A violência na escola. São Paulo: Summus, 1989.

DUSCHATZKY, Silvia e SKLIAR, Carlos. O Nome dos Outros, Narrando a alteridade na cultura e na educação. In Larrosa, J e Skliar, C. Habitantes de Babel: políticas e poéticas da diferença. Belo Horizonte: Autêntica, 2001.

FOUCAULT, Michel. A Escrita de Si. In: Ditos $e$ Escritos V: Ética, Sexualidade, Política. Rio de Janeiro: Forense Universitária, 2004a.

FOULCAULT, Michel. A Hermenêutica do Sujeito. São Paulo: Martins Fontes, 2004b.

GALLO, Silvio. Entre Édipos e O Anti-Édipo: estratégias para uma vida não fascista. In RAGO, Margareth e VEIGA-NETO, Alfredo. Para uma vida não fascista. Belo Horizonte: Editora Autêntica, 2009.

GATTI, Bernadete Angelina. Grupo focal na pesquisa em Ciências Sociais e Humanas. Brasília: Liber Livro Editora, 2005.

GONÇALVES, Luis Alberto Oliveira; SILVA, Petronilha Beatriz Gonçalves. $O$ jogo das diferenças: o multiculturalismo e seus contextos. 3 . Ed. - Belo Horizonte: Autêntica, 2002.

LARROSA, Jorge. "Tecnologias do $\mathrm{Eu}$ e Educação" In: SILVA, T. T. $O$ Sujeito da Educação: Estudos Foucaultianos. Petrópolis: Ed. Vozes, 1994.

LARROSA, Jorge. Notas sobre a experiência e o saber de experiência. Revista Brasileira de Educação, n. 19, p. 20-28, jan-abr. 2002. Disponível em http://www.anped.org.br/rb e/rbedigital/rbde19/rbde19_04_jorge_larrosa_bondi a.pdf, dia 24 de Setembro de 2012, às 10h58.

LOPES NETO, Aramis Antonio. Bullying -
Comportamento agressivo entre estudantes. Jornal de pediatria.v. 81, n. 5 (supl.), 2005. Disponível em: <http://www.scielo.br/pdf/jped/v81n $5 \mathrm{~s} 0 / \mathrm{v} 81 \mathrm{n}$ 5Sa06.pdf $>$.

NIETZSCHE, Friedrich Wilhelm. Assim Falou Zaratustra. Rio de Janeiro: Civilização Brasileira, 1983.

OLIVEIRA, Flavia Fernandes de; VOTRE, Sebastião Josué. Bullying na aulas de educação física. Revista Movimento. Porto alegre, v. 12, n. 2 , mai. lago. 2006. Disponível em: <www.seer.ufrgs.br/index.php/movimento/article/vi ew/2900/1536>. Acesso em: 24 de jun. de 2008.

OLIVEIRA, Iolanda (org.). Relações raciais $e$ educação: novos desafios. Rio de Janeiro: DP\&A, 2003.

PIERUCCI, Antônio Flávio. Ciladas da diferença. Tempo Social. Ver. Sociol. USP, S. Paulo, 2(2): 733, 2. sem., 1990.

TURA, Maria de Lourdes Rangel. A observação do cotidiano escolar. In: ZAGO, Nadir; CARVALHO, Marília Pinto de; VILELA, Rita Amélia Teixeira (orgs). Itinerários de pesquisa: Perspectivas qualitativas em Sociologia da Educação. Rio de Janeiro: DP\&A, 2003.

TÜRCKE, Christoph. Sociedade excitada: filosofia da sensação. Editora da Unicamp, Campinas, 2010.

WAISELFISZ, Julio Jacobo. Mapa da Violência 2012:A Cor dos Homicídios no Brasil / JulioJacoboWaiselfisz - Rio de Janeiro: CEBELA, FLACSO; Brasília: SEPPIR/PR, 2012.

ZUIN, Antonio Álvaro Soares. Adoro odiar meu professor: o aluno entre a ironia e o sarcasmo pedagógico. Campinas, SP: Autores Associados, 2008.

\section{Sobre as autoras}

Elise Helena de Morais Batista é Mestre em Educação pela Faculdade de Educação da UNICAMP. Educadora Física e Pedagoga. Pesquisadora do Grupo Violar da Faculdade de Educação da UNICAMP - Campinas. Desde 2013 é Coordenadora Pedagógica da Prefeitura Municipal de Campinas. 
Maria Teresa de Arruda Campos é Psicóloga e Pedagoga. Mestre e doutora pela Faculdade de Educação/Unicamp. Pesquisadora do Grupo Violar. Consultora de projetos para administração pública. Desde 2009 é superintendente do Arquivo Público e Histórico de Rio Claro.

Recebido em junho de 2015.

Aprovado em novembro 2015. 